\title{
Review of Vitamin B12 deficiency in pregnancy - a diagnosis not to miss as veganism and vegetarianism become more prevalent
}

\author{
sabia rashid ${ }^{1}$, violet meier ${ }^{1}$, and Hannah Patrick ${ }^{1}$ \\ ${ }^{1}$ Lewisham and Greenwich NHS Trust
}

August 17, 2020

\begin{abstract}
Vegetarianism and veganism are increasingly popular. However, veganism risks development of vitamin B12 deficiency as it is not available from plant sources. Moreover, its impact may be slow to be detected because body stores of vitamin B12 can last years. There is currently no UK guidance on antenatal diagnosis and management of vitamin B12 deficiency. This paper reviews the metabolism, diagnosis and treatment of vitamin B12 in pregnancy. It concludes that prophylactic vitamin B12 supplementation should be given to high risk groups around the time of pregnancy.
\end{abstract}

\section{Hosted file}

JRCOG v0.4.docx available at https://authorea.com/users/351412/articles/476171-reviewof-vitamin-b12-deficiency-in-pregnancy-a-diagnosis-not-to-miss-as-veganism-andvegetarianism-become-more-prevalent 